IZA DP No. 10276

\title{
A Life Course Approach to Understanding Neighbourhood Effects
}

Elise de Vuijst

Maarten van Ham

Reinout Kleinhans

October 2016 


\title{
A Life Course Approach to Understanding Neighbourhood Effects
}

\author{
Elise de Vuijst \\ Delft University of Technology \\ Maarten van Ham \\ Delft University of Technology \\ and IZA \\ Reinout Kleinhans \\ Delft University of Technology
}

\section{Discussion Paper No. 10276 \\ October 2016}

\author{
IZA \\ P.O. Box 7240 \\ 53072 Bonn \\ Germany \\ Phone: +49-228-3894-0 \\ Fax: +49-228-3894-180 \\ E-mail: iza@iza.org
}

\begin{abstract}
Any opinions expressed here are those of the author(s) and not those of IZA. Research published in this series may include views on policy, but the institute itself takes no institutional policy positions. The IZA research network is committed to the IZA Guiding Principles of Research Integrity.

The Institute for the Study of Labor (IZA) in Bonn is a local and virtual international research center and a place of communication between science, politics and business. IZA is an independent nonprofit organization supported by Deutsche Post Foundation. The center is associated with the University of Bonn and offers a stimulating research environment through its international network, workshops and conferences, data service, project support, research visits and doctoral program. IZA engages in (i) original and internationally competitive research in all fields of labor economics, (ii) development of policy concepts, and (iii) dissemination of research results and concepts to the interested public.
\end{abstract}

IZA Discussion Papers often represent preliminary work and are circulated to encourage discussion. Citation of such a paper should account for its provisional character. A revised version may be available directly from the author. 


\section{ABSTRACT}

\section{A Life Course Approach to Understanding Neighbourhood Effects*}

Many theories on so-called neighbourhood effects - effects of the residential context on individual outcomes such as employment, education, and health - implicitly, or explicitly suggest lagged effects, duration effects, or for example, intergenerational effects of neighbourhoods. However, these temporal dimensions of neighbourhood effects receive only limited attention in the empirical literature, largely because of a lack of suitable data. The increasing availability of geo-coded, longitudinal, individual-level data now leads to more research which takes these temporal dimensions and time effects into account. This paper argues that it is time for an overarching framework to better understand the temporal dimension of neighbourhood effects. We propose a conceptual model that uses the life course approach as a framework to integrate the various elements of time in current neighbourhood effects theories. The life course approach emboldens the study of full individual life course biographies over time, taking into consideration multiple parallel life careers (such as education, household, housing, work, and leisure) and their relative importance to individual outcomes. A large advantage of the life course approach to neighbourhood effects is that it does not only allow us to incorporate residential neighbourhoods into individual biographies, but also allows us to study the effects of (and interactions with) other social and spatial contexts on individual outcomes.

JEL Classification: $\quad$ I30, J60, P46, R23

Keywords: neighbourhood effects, neighbourhood histories, life course approach, temporal dimension, contextual effects

Corresponding author:

Elise de Vuijst

OTB - Research for the Built Environment

Faculty of Architecture and the Built Environment

Delft University of Technology

P.O. box 5043

2600 GA, Delft

The Netherlands

E-mail: E.deVuijst@tudelft.nl

\footnotetext{
* The research leading to this paper has received funding from the European Research Council under the European Union's Seventh Framework Programme (FP/2007-2013) / ERC Grant Agreement no. 615159 (ERC Consolidator Grant DEPRIVEDHOODS, Socio-spatial Inequality, Deprived Neighborhoods, and Neighborhood Effects); and from the Marie Curie programme under the European Union's Seventh Framework Programme (FP/2007-2013) / Career Integration Grant no. PCIG10-GA2011-303728 (CIG Grant NBHCHOICE, Neighborhood Choice, Neighborhood Sorting, and Neighborhood Effects).
} 


\section{Introduction}

There are many theories on the effect of the neighbourhood on individual outcomes in life, most of which contain some explicit or implicit reference to the importance of time (Sharkey and Elwert 2011; Musterd et al. 2012; Galster 2012; van Ham et al. 2014). For example, long-term exposure to neighbourhood characteristics is often assumed to have a stronger effect on residents than short-term exposure. Furthermore, the frequency and intensity of exposure over time are believed to determine the strength of potential neighbourhood effects (ibid.). However, despite the acknowledgement that time is important, the temporal dimension remains implicit in many studies, and empirically, time still gets limited attention. There are two main reasons for this: first, and practically, in many countries, there is a substantial lack of adequate, geocoded longitudinal data, with Sweden and the Netherlands as major exceptions. Many studies still rely on cross-sectional data, or longitudinal data collected over short periods of time; such data are inadequate to properly address temporal dimensions of neighbourhood effects. Second, while time is recognised to play an important role in the effect of the neighbourhood on individual outcomes, there is no overarching theoretical framework that explicitly places the temporal dimension at the heart of understanding neighbourhood effects. We argue that the temporal dimension is crucial and should therefore receive more explicit attention both conceptually and empirically.

In this paper, we propose a life course approach to the study neighbourhood effects: a comprehensive and dynamic spatial-temporal framework, in which theory and empirics can meet. A life course approach enables researchers to take into consideration a full individual biography comprised of numerous states, events, and experiences over time. From a life course perspective, any point over an individual's life course, for instance their residence in a particular neighbourhood, is seen as inescapably related to their foregoing and ongoing experiences (Dykstra and van Wissen 1999; Feijten 2005; Feijten et al. 2008). Vital to a life course approach, such previous experiences are not necessarily limited to the direct context, or career, in which a life event takes place (ibid.). For example, a period of residence in a deprived neighbourhood belongs to an individual's housing history. Nevertheless, following a life course approach, this experience must always be seen in light of other life events, related to household, education, and the labour market, as they are fundamentally interrelated and can accumulate in their effects over time (Feijten et al. 2008; de Vuijst et al. 2015). Applied to the study of neighbourhood effects, this approach can thus enable researchers to examine how neighbourhood experiences are embedded in larger individual neighbourhood careers and biographies over the life course (Feijten 2005; Aisenbrey \& Fasang 2010; de Vuijst et al. 2015), and assess the relative importance of events in parallel careers on particular individual outcomes (Geist \& McManus 2008; van Ham et al. 2014). As such, this approach can make it easier to think about time when looking at neighbourhood effects, and can be seen as an effective tool to help explicitly integrate the temporal dimension into these studies.

Adopting a life course approach to understanding neighbourhood effects has the additional advantage that further careers, other than the residential neighbourhood trajectory, can be integrated into a single framework of time and space. We argue that when focussing on neighbourhood effects, research should also take into account the effects of a broader set of contextual effects on individual outcomes, where the residential neighbourhood is only one of the relevant contexts (see also van Ham and Tammaru 2016 for a thorough discussion). The residential neighbourhood remains important in our daily lives, but other life careers such as work and school trajectories also influence individual outcomes, possibly in interaction with the residential neighbourhood context. We argue that to move forward our understanding of neighbourhood effects, the residential career must be seen as fundamentally interrelated to further life careers, and the residential space may no longer be the main socio-spatial context in 
which these careers unfold, and to which individuals are exposed on a daily basis (Manley 2014; Kwan 2012; van Ham and Manley 2012; Wheaton and Clarke 2003; van Ham and Tammaru 2016). The proposed life course approach to neighbourhood effects can capture individual experiences in parallel housing, household, education, and labour market careers, that unfold within multiple socio-spatial contexts over time.

\section{Neighbourhood histories of individuals}

Before setting out in detail how the life course approach can help to better understand neighbourhood effects, we first review a number of recent studies that look at the neighbourhood histories of individuals, as well as studies that explicitly enter time and neighbourhood histories into models of neighbourhood effects. Reviewing these studies and findings, we focus specifically on the role of time.

A small number of recent studies has investigated the neighbourhood histories of individuals, including intergenerational transmission of neighbourhoods, and the effect of these neighbourhood histories on individual outcomes. Although not explicitly stated, these studies have adopted elements from the life course approach to the study of neighbourhood effects, and by doing so they yielded new and important findings. In the United States, longitudinal neighbourhood research has shown intergenerational neighbourhood stratification along socioeconomic lines (Vartanian et al. 2007; Sharkey 2008), where growing up in the poorest quarter of American neighbourhoods meant remaining in these poorest neighbourhoods as adults in more than $40 \%$ of cases for whites, and $70 \%$ of cases for blacks (Sharkey 2008). This persistence also entailed intergenerational transmission of racial inequality in individual outcomes, as black Americans were more likely to continuously reside in deprived neighbourhoods, and thus to be exposed to localised disadvantage (Sharkey 2008). In a followup study by Sharkey and Elwert (2011), which we will discuss in more detail later on, spatial characteristics were shown to not only affect the neighbourhood outcomes of children, but also those of grandchildren. These results thus support the assumption that neighbourhood experiences over time are linked to a range of outcomes spanning across several generations, suggesting multi-generational continuity.

Van Ham and colleagues (2014) analysed the population of the Stockholm metropolitan area, and followed the neighbourhood outcomes of individuals up to almost 20 years after leaving the parental home (also see Hedman et al. 2013). Using Swedish register data, the researchers were able to access yearly neighbourhood and income characteristics for all inhabitants, and subsequently defined spatial deprivation based on percentages of poor neighbours in the residential environment. Individuals were considered to be poor if their income was part of the lowest $20 \%$ of incomes in Stockholm. Results showed that children from deprived parental neighbourhoods were likely to spend time in similarly deprived neighbourhoods as adults, and that long-term exposure to localised poverty further increased this likelihood within personal neighbourhood histories (Hedman et al. 2013; van Ham et al. 2014). Table 1 shows results on the cumulative exposure; the percentage of years that individuals are exposed to five categories of neighbourhood deprivation over the measurement period (by the parental neighbourhood at the start of the observation) (source: van Ham et al. 2014). 
Table I. Cumulative exposure to neighbourhood income quintiles 1991-2008 (years of exposure as percentage of total years )

\begin{tabular}{|c|c|c|c|c|c|c|}
\hline \multirow[b]{2}{*}{$\begin{array}{l}\text { Parental neighbourhood } \\
\text { in } 1990 \text { (quintiles) }\end{array}$} & \multicolumn{6}{|c|}{$\begin{array}{l}\text { Cumulative exposure to neighbourhood income quintiles 1991- } \\
2008\end{array}$} \\
\hline & 1 & 2 & 3 & 4 & 5 & Total \\
\hline $\begin{array}{l}1 \text { Low poverty } \\
\text { neighbourhood }\end{array}$ & 17.9 & 14.9 & 16.0 & 20.6 & 30.6 & 100 \\
\hline 2 & 16.3 & 14.7 & 16.9 & 21.9 & 30.3 & 100 \\
\hline 3 & 13.1 & 12.8 & 16.9 & 23.6 & 33.6 & 100 \\
\hline 4 & 10.6 & 10.9 & 15.7 & 24.4 & 38.3 & 100 \\
\hline $\begin{array}{l}5 \text { Poverty concentration } \\
\text { neighbourhood }\end{array}$ & 8.9 & 9.0 & 13.1 & 20.3 & 48.8 & 100 \\
\hline
\end{tabular}

Source: Authors calculations on GeoSweden dataset

In the Netherlands, de Vuijst et al. (2015) implemented the same definition of spatial deprivation to that used in the previously described Swedish study, and used Dutch register data to follow a complete cohort of parental home-leavers over a 14-year period, 1999 to 2012. The researchers analysed the effect of the parental neighbourhood on the neighbourhood outcomes of their children over time, and found that after leaving the parental home, the characteristics of the parental neighbourhood continued to have a strong effect on the neighbourhood histories of their children, even after controlling for parental income and the socio-economic attainments of their children over the life course (de Vuijst et al. 2015). These results were very similar to those found in the Stockholm metropolitan area. Figure 1 shows a sequence-index plot of individual neighbourhood histories in the measurement period, where each horizontal line represents an individual trajectory. If the colour of the line changes between years, the individual moved to a neighbourhood with a different level of localised poverty (see de Vuijst et al. 2015 for a more detailed description of the method and output).

Figure I. Sequence plot on pattems of individual neighbourhood histories in the Netherlands 19992012 (on a sample of 5000 individual histories) of those leaving the parental home in 1999-2000, by parental neighbourhood quintiles (1: lowest poverty concentration)
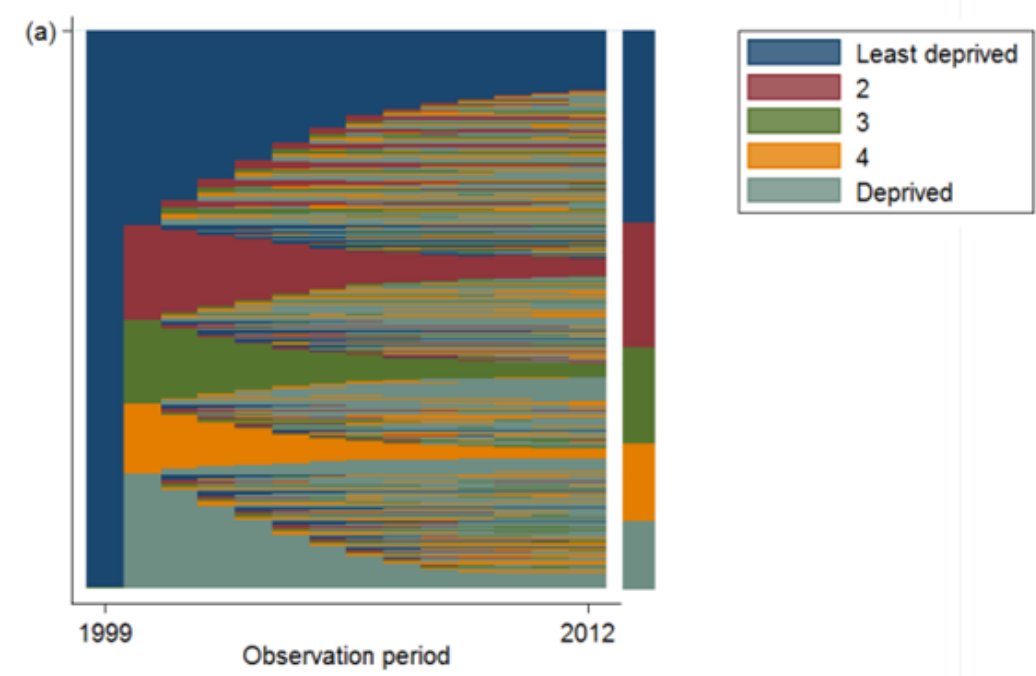

Source: author calculations on Statistics Netherlands, System of Social Statistical Database 
In both Sweden and the Netherlands, intergenerational neighbourhood patterns were shown to be much stronger for non-western ethnic minorities than for other groups (van Ham et al. 2014; de Vuijst et al. 2015). In the Netherlands, further analyses showed that individuals from deprived parental neighbourhoods can discontinue these intergenerational patterns of spatial deprivation when they attain higher education over time. In other words, higher education attainment can break the link between the neighbourhood where children grew up, and their residential outcomes as adults later in life. This discontinuation was however shown to be less prevalent for individuals from ethnic minority groups (de Vuijst et al. 2015).

Naturally, there are large differences between the USA, The Netherlands, and Sweden with regard to their societal and political structure and organisation, including their welfare systems. Furthermore, the data used, as well as the neighbourhood definitions, differ substantially between the studies described. Nevertheless, the above findings do suggest that individual neighbourhood outcomes in life are strongly path dependent; 'enclosed' as it were, in past residential experiences, which span across generations (and societies) through childhood experiences in the parental home. Therefore, combined, they suggest a clear benefit of adopting a life course approach to the study of neighbourhood effects over time, which we will explore in more depth below.

\section{Time and neighbourhood effects}

In addition to studies focussing on the path dependence of individual neighbourhood histories, tracking individual residential settings over time, a number of studies also use these neighbourhood histories as an explanation of certain individual outcomes in life. These studies emphasise the need to look at a variety of time elements in personal neighbourhood experiences. To illustrate, Galster (2012) suggests a number ways in which exposure to the residential environment could determine the strength of its potential effects. Following on from his work, it has repeatedly been suggested that the frequency and intensity of exposure to the neighbourhood over time, as well as the duration of the exposure are vital in assessing the connection between neighbourhood characteristics and individual outcomes over time (Sharkey \& Elwert 2011; Musterd et al. 2012; Galster 2012; van Ham et al. 2014; de Vuijst et al. 2015). We will now give two examples of studies that have explicitly included time in their examination of neighbourhood effects.

In Sweden, Hedman and colleagues (2013) use a population of parental home-leavers in Stockholm, Sweden, to study the effect of two separate temporal dimensions of exposure to neighbourhood environments on personal income over time: the parental neighbourhood, measured at the time the research population left the parental home, and cumulative exposure to neighbourhood poverty in the following 17 years. The researchers found independent effects on income of both temporal dimensions. A deprived parental neighbourhood was clearly shown to have a negative effect on individuals' income later in life, up to the end of the measurement period. Furthermore, higher levels (more years) of exposure to concentrated poverty neighbourhoods, especially later in life, were shown to have a strong negative effect on later income levels.

In United States, Sharkey and Elwert (2011), as briefly mentioned above, stress the fact that research into neighbourhood effects on child development has largely overlooked the temporal dimension. A child's neighbourhood environment may influence their developmental outcomes and cognitive ability in numerous ways, for instance through the quality of their available schooling system and experience, or the influence of their peers (ibid.). The results indicate that the neighbourhood environment and cognitive ability are strongly connected: exposure to deprived neighbourhoods across two consecutive generations strongly reduces child cognitive ability. In other words, growing up in poverty concentration in one generation has a strong negative effect on child cognitive ability in the following generation. 


\section{A life course approach}

Taking into consideration the findings of the aforementioned studies, on intergenerational transmission of neighbourhood characteristics, the path dependence of individual neighbourhood histories, and examples of neighbourhood histories as an explanatory factor to various individual outcomes, we will introduce the life course approach as an overarching conceptual framework.

An individual life course consists of a succession of events and transitions that unfold within several socio-spatial contexts. People get married; buy a house; become parents; retire; and all of these experiences fundamentally alter their lives and behaviour. From early on in the literature, we find a consensus on an important underlying structure to these event-successions, which is the seemingly simple concept of "time" (Hareven 1977; Heinz 1991; Elder 1994; Dykstra \& van Wissen 1999). Time, and its possible elements in effects and patterns, began to be seen as the ultimate means to gain insight into aspects of individual behaviour. In line with this conviction, there was an upsurge in the field of life course studies from the 1940s onwards (Hareven 1977). Life course theory quickly established itself as a distinct theoretical and methodological outlook in the social sciences, focussing on complexities and themes in individual behaviour and experiences over time: “(...) an appreciation of 'the long way' of thinking about human personality and its social pathways in changing societies” (Elder 1994, p. 4).

In life course theory, any point in an individual life is considered inescapably related to their foregoing events and transitions over time (Hareven 1977; Dykstra \& van Wissen 1999). As such, life events and states are in constant flux, and their transitions make up multiple dynamic, rather than static, life course careers or trajectories (Sampson et al. 2002; van Ham et al. 2014; de Vuijst et al. 2015). Careers can be formed within every vital life theme that is subject to change over time, ranging from education, work, and leisure, to housing and household formation (Elder 1985; Willekens 1999). Central to life course theory is the notion that experiences and pressures in one career can accelerate or hinder what happens in other careers as there are links between their events (Dykstra \& van Wissen 1999; Willekens 1999). For example, financial problems due to job loss can influence household behaviour, for instance by negatively affecting marriage quality or decisions on family planning. Given these dependencies between life careers, the life course must be viewed as a multilevel phenomenon. Important life events and transitions are shown to take place due a variety of reasons or causes. Events can be the result of intentional individual choices, i.e. "I will buy a house", or they can be caused by other events taking place around the individual, either at the micro-level; "Susie is leaving John, i.e. John is now single", or at the macro-level; "John just turned 67, i.e. John has to leave the labour market because of his retirement age”. Additionally, at the macro-level, individual lives can be shaped due to persistent societal norms and values (Dykstra \& van Wissen 1999). For this reason, a life course approach does not only introduce the importance of thinking about time when looking at life events within life course pathways, it further sets out the life course as an inherently multilevel phenomenon throughout time, and life course study as an intrinsically and necessarily interdisciplinary field (Elder 1994; also see Dykstra \& van Wissen 1999). 
Time elements to effects over the life course

An effect on a personal outcome, and the relation to its cause, can differ in timing, duration and order (Feijten 2005). Therefore, life course theory builds on the basic underlying principle that effects of events within life careers, in addition to the events themselves, are fundamentally time-variant (Feijten 2005; Feijten et al. 2008; see also Blossfeld \& Mills 2001). We will explain these time elements in more detail.

First of all, in relation to timing, effects can be either immediate, or they can be lagged. In lagged effects, an effect takes time to manifest itself (Feijten 2005). Therefore, the relation between the cause and a lagged effect can easily be overlooked when analysing cross-sectional data, as they may miss either the cause or the effect in their timespan. A clear example of a lagged effect is that going to a specific school during childhood, can result in long lasting friendships and memberships of networks, which can help in finding a job later in life, or even a partner. The latter event is an effect of the former experience.

Second of all, effects can either last or not, and research on short spells of data cannot capture the duration of effects on individual outcomes (ibid.). So, for example, growing up in a deprived neighbourhood might have a short term effect on individual labour careers while the effect can wear off with age, but the effect might also be long-lasting, even further into adulthood. Therefore, temporary effects run the risk of being over- or under-estimated, and incorrect assumptions about their relative importance and persistence over time are all too easy to make.

Finally, the order between cause and effect is not as straightforward as one would think. Even though the notion of causality dictates that effects occur after its causes, they can in fact be anticipative. Young couples may for instance move to a suburban area in anticipation of starting a family, in which case the moving behaviour and the subsequent birth of a child are again linked, in that order. For anticipative behaviour, patterns can be even more difficult to discern when events and effects are not observed over time (ibid.). The aforementioned examples also shows a lagged effects (anticipation) across careers, namely the housing and household career, showing that anticipation can only be detected if events and effects across multiple careers are simultaneously observed over time. In short, as demonstrated above, conclusions on effects drawn from point-in-time data focussing on individuals' current state and its instantaneous effect on current individual-level outcomes cannot capture the timevariant nature of both event and effect (van Ham et al. 2014; de Vuijst et al. 2015).

There are other fields of research that have studied the temporal dimension to spatial patterns, for instance in the study of the residential environment and housing careers over time (Clark \& Huang 2003; Feijten \& Mulder 2005). Some of these studies have explicitly applied a life course approach. For example, research has focussed on tracking mobility across neighbourhoods over the life course, and has examined the effect of several personal and spatial characteristics on upward or downward trajectories with regard to neighbourhood quality. Studies focussing on the effects of public housing or welfare support, for instance, have persistently shown that these factors result in less upward spatial mobility over time (South \& Crowder 1997; Vartanian et al. 2007), whereas increases in socioeconomic resources had the opposite effect (Clark et al. 2003). For ethnic minority groups, it was shown to be more common to reside in neighbourhoods with high concentrations of poverty, or to lack access to adequate social provisions, in comparison to other residents and neighbourhoods over time (Crowder \& South 2005; Vartanian et al. 2007; Simpson \& Finney 2009; van Ham et al. 2014; de Vuijst et al. 2015). Furthermore, children were shown to prefer similar types of accommodation to their parents with regard to homeownership, which subsequently affected their choice of neighbourhoods throughout life (Kurz 2004; Helderman \& Mulder 2007; Feijten et al. 2008). It is clear from these findings that a focus on the temporal dimension to spatial characteristics and outcomes is crucial, and has enormously benefited these fields of research in their ability 
to identify the relative importance of these characteristics over time. Cross-sectional studies could not have revealed the results and effects described above, and our insights into these spatial patterns would still have been limited. It is interesting to note that when examining both the theoretical approaches and the analytical methods used in this mobility research, they are certainly translatable to the study of neighbourhood effects.

\section{A conceptual model of the life course approach to neighbourhood effects}

Following our discussion above, we present a conceptual model (Figure II) which brings together elements from the life course approach with elements from neighbourhood effects theory. The model explicitly takes inspiration from time-space geography by Hägerstrand (1970) by graphically illustrating the idea that over the life course an individual follows a certain path through space and time, incorporating various spatial contexts such as the residential neighbourhood where one lives (home), but also other contexts such as places of work, leisure and schools. We argue that this model enables researchers to take into consideration a full individual biography comprised of numerous states, events, spells, and their effects on individual outcomes over time (Feijten et al. 2008; de Vuijst et al. 2015). Our conceptual model captures the essence of the life course approach to neighbourhood effects, looking at individual experiences in parallel housing, household, education, and labour market careers that unfold within multiple socio-spatial contexts over time.

Figure II. A conceptual model of the life course approach to neighbourhood effects

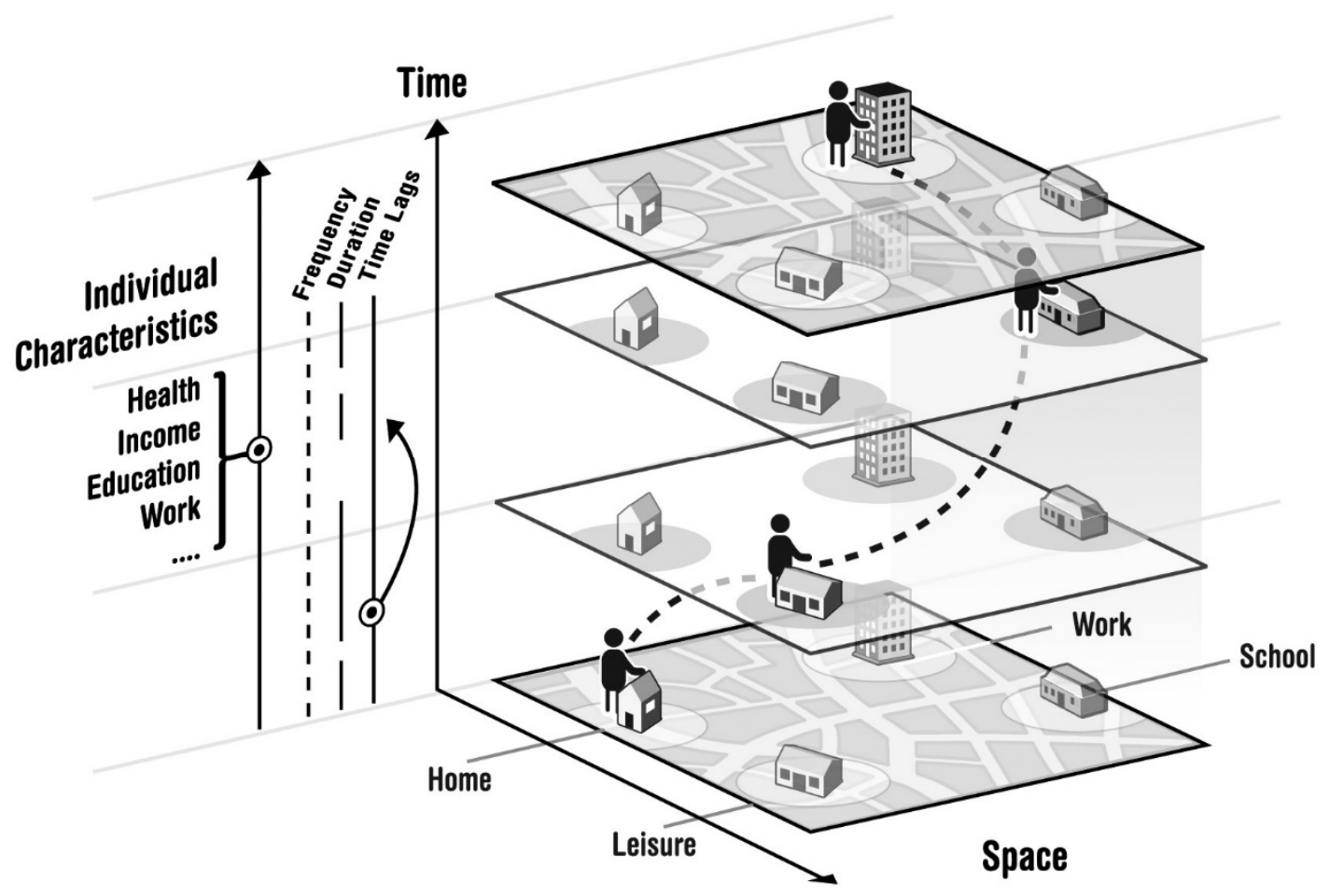

Source: authors

The key interest in Figure II lies in the dot which lists individual outcomes on the solid far-left line, with examples such as health; income; education; and work. From a neighbourhood effects perspective, we aim to understand these individual outcomes in a variety of careers, from residential contexts in which people live or have lived in the past. The right side of figure II 
depicts an individual time-space path, where time can consist of periods or even a life time, in which a person spends time in a variety of spaces related to home, school, leisure, work, and other spatial contexts. Therefore, the conceptual model explicitly takes into account the effects of other contexts than the residential neighbourhood. The relationship between these (combined) spatial contexts and the time spent in each of these contexts lies in the time effects of frequency, duration, and time-lags. On the left side of the figure, these three dimensions are illustrated by the dotted, broken and solid lines between the two upward arrows indicating time. As discussed above, frequency refers to the number of spells spent in a certain spatial context, while duration refers to the duration of these spells. The time-lags indicate the potential of past experiences in certain spaces to influence individual outcomes (much) later in life.

When using a life course approach to neighbourhood effects, rather than just identifying the occurrence of a neighbourhood event, the event and its effects can be placed within a full individual biography over time and space, which enables research into the order and the timing of these occurrences, as well as their duration (Giele \& Elder, 1998; Feijten, 2005). As such, researchers can examine the ways in which a neighbourhood experience is embedded within individual careers at large (Feijten 2005; Aisenbrey \& Fasang 2010; de Vuijst et al. 2015), and assess the relative importance of these events and their effects to certain individual outcomes (Geist \& McManus 2008; de Vuijst et al. 2015). By applying this approach to the study of neighbourhood effects, therefore, empirical studies can specifically focus on the temporal dimension to spatial effects, and further determine time elements that affect the nature and strength of these effects, the importance of which has been stressed throughout literature in the past (for example, see Galster 2012).

As stated, the integration of a life course approach in the study of neighbourhood effects can be highly instructive as it encourages simultaneous research into parallel life careers, and the various socio-spatial contexts in which they unfold. The neighbourhood is only one area in which exposure to, for instance, spatial or income deprivation can take place, but poverty concentration at the school or work environment may equally influence individual outcomes over time, within a range of life careers. Therefore, a life course approach may not only serve as an overarching conceptual framework to integrate the temporal dimension into the study of neighbourhood effects, but it also has the ability to bring together separate bodies of literature on vital life themes; the significance and interaction of which can only be understood in relation to other careers. This latter benefit further suits the current discussion on the relative importance of the residential location. After all, while the neighbourhood was once the hub of social interaction in everyday life, one can now equally, or more so, be influenced by the work or educational settings they frequent, by places of leisure and travel (Manley 2014; Kwan 2012; van Ham and Manley 2012; Wheaton and Clarke 2003; van Ham and Tammaru 2016), or even by online interactions in popular social media, which are not connected to a particular career. For this reason, the life course approach neatly fits into the steps that have already been made in the neighbourhood effects literature over the last decades; both for those steps in which theory has been developed on the importance of time to the effect of the residential environment, and for the steps made by those arguing for an extension of the research focus on the residential environment alone. Integrating the life course approach into neighbourhood effects research allows researchers to take into consideration contextual effects over time, if you will; a terminological notion that can bring the neighbourhood effects literature forward both on the conceptual and methodological front. The life course approach can tick all the boxes given our current theoretical outlook and our everyday socio-spatial interaction patterns. 


\section{Conclusion}

In this paper, we propose that the application of a life course approach to the study of neighbourhood effects can bring the field forward. Many theories on the effect of the residential environment on individual outcomes recognise that time can play an important role in determining spatial effects. Nevertheless, this temporal dimension does not receive the empirical attention it should, because it has remained implicit in the bulk of research into neighbourhood effects. There are multiple time elements to neighbourhood exposure, such as its duration, frequency, and intensity that are strongly believed to determine the nature and strength of potential neighbourhood effects (Musterd et al. 2012; Galster 2012; de Vuijst et al. 2015). In addition to practical limitations, such as the absence of adequate longitudinal data, we argue that there is a more profound, conceptual issue at the core of this problem. The neighbourhood effects literature fundamentally lacks an overarching theoretical framework that could integrate the temporal dimension into its research output, and form the much desired link between theory and empirics. In this paper, we put forward the life course approach as the ultimate conceptual framework, and an effective tool, to bring about this change. It eases the thought of time with regard to spatial effects, and further encourages the integration of separate bodies of literature on vital life themes, within various socio-spatial contexts, into one, comprehensive research setting.

A life course approach, which basically reflects a "long way" of thinking about individual human trajectories over time, views life and its life course careers as both fundamentally time-variant notions as well as necessarily multilevel concepts. It introduces the importance of thinking about time when looking at successions of events in central life themes, and acknowledges the variety of reasons and causes that may be behind these transitions. Vital to this approach, life course theory stresses the dependencies between both causes and events throughout various careers and socio-spatial contexts. An event or outcome within one pathway in life can only be seen in relation to both foregoing and current experiences in parallel careers. Life course study must therefore always be seen as intrinsically interdisciplinary (Elder 1994), and can greatly benefit the body of the neighbourhood effects literature. Adopting a life course approach encourages the application of a dynamic spatial-temporal research framework in the study of neighbourhood effects, and enables researchers to examine how neighbourhood experiences are embedded in individual neighbourhood biographies over time (Feijten 2005; Aisenbrey \& Fasang 2010; de Vuijst et al. 2015; Geist \& McManus 2008; van Ham et al. 2014). Additionally, studies can capture individual experiences in parallel housing, household, education, and labour market careers, unfolding within multiple socio-spatial contexts over time, and thus simultaneously assess their relative importance to individual outcomes over the life course. In doing so, researchers can gain valuable insights into patterns and trends over time, assess the timing, duration and order of cause and effect, and take a broader stance on contextual effects on individual outcomes at large. As such, a life course approach has the potential to combine insights from results on multiple topics of interest, and to bring together these separate bodies of literature, in addition to integrating the temporal dimension into the study of neighbourhood effects. The few neighbourhood effects studies that have focused on spatial effects over time, have clearly illustrated the benefit of conducting thorough longitudinal research within a life course framework. They have provided us with information that has changed our understanding of spatial patterns and effects over time, as well as the way we think about the importance of time to neighbourhood effects. In this paper, we have provided a conceptual model that will effectively facilitate researchers to conduct longitudinal research within a life course framework. Inspired by Hägerstrand's time-space geography, our graphically depicted conceptual model integrates elements from the life course approach with neighbourhood effects theory. By introducing this conceptual model, we make the case that a 
life course approach can neatly fill the gap so repeatedly pointed out within the neighbourhood effects literature, and can help future research over the crossroads and further the debate.

\section{References}

Aisenbrey, S., \& Fasang, A. E. (2010). New life for old ideas: The" second wave" of sequence analysis bringing the" course" back into the life course. Sociological Methods \& Research, 38(3), 420-462.

Blanden, J., Gregg, P., \& Machin, S. (2005). Intergenerational Mobility in Europe and North America. London. London School of Economics. Centre for Economic Performance.

Bloome, D. (2014). Racial Inequality Trends and the Intergenerational Persistence of Income and Family Structure. American Sociological Review, 79(6), 1196-1225, doi:10.1177/0003122414554947.

Blossfeld, H.-P., \& Mills, M. (2001). A Causal Approach to Interrelated Family Events: A Cross-National Comparison fo Cohabitation, Non-marital Conception, and Marriage. Canadian Studies in Population, 28(2), 409-437.

Clark, W. A., \& Huang, Y. (2003). The life course and residential mobility in British housing markets. Environment and Planning A, 35(2), 323-340.

de Vuijst, E., van Ham, M., \& Kleinhans, R. (2015). The Moderating Effect of Higher Education on Intergenerational Spatial Inequality.

Dykstra, P. A., \& van Wissen, L. J. (1999). Introduction: The life course approach as an interdisciplinary framework for population studies. In Population Issues (pp. 1-22): Springer.

Elder Jr, G. H. (1985). Perspectives on the life course.

Elder Jr, G. H. (1994). Time, Human Agency, and Social Change: Perspectives on the Life Course. Social Psychology Quarterly, 57(1), 4-15, doi:10.2307/2786971.

Feijten, P. (2005). Life events and the housing career: A retrospective analysis of timed effects: Eburon Delft.

Feijten, P., Hooimeijer, P., \& Mulder, C. H. (2008). Residential experience and residential environment choice over the life-course. Urban Studies, 45(1), 141-162.

Galster, G. C. (2012). The Mechanism(s) of Neighbourhood Effects: Theory, Evidence, and Policy Implications. In M. van Ham, D. Manley, N. Bailey, L. Simpson, \& D. Maclennan (Eds.), Neighbourhood Effects Research: New Perspectives (pp. 23-56): Springer Netherlands.

Geist, C., \& McManus, P. A. (2008). Geographical mobility over the life course: motivations and implications. Population, Space and Place, 14(4), 283-303, doi:10.1002/psp.508.

Giele, J. Z., \& Elder, G. H. (1998). Methods of life course research: Qualitative and quantitative approaches: Sage Publications. 
Hägerstrand, T. (1970). What About People in Regional Science? Papers of the Regional Science Association 24, 7-21.

Hareven, T. K. (1977). Family time and historical time. Daedalus, 57-70.

Hedman, L., Manley, D., van Ham, M., \& Östh, J. (2013). Cumulative exposure to disadvantage and the intergenerational transmission of neighbourhood effects. Journal of Economic Geography, doi:10.1093/jeg/lbt042.

Heinz, W. R. (1991). Status passages, social risks and the life course: A conceptual framework. Theoretical advances in life course research, 1, 9-22.

Kwan, M.-P. (2012). The uncertain geographic context problem. Annals of the Association of American Geographers, 102(5), 958-968.

Manley, D. (2014). Scale, Aggregation, and the Modifiable Areal Unit Problem. In M. M. Fischer, \& P. Nijkamp (Eds.), Handbook of Regional Science (pp. 1157-1171): Springer Berlin Heidelberg.

Mulder, C., \& Hooimeijer, P. (1999). Residential Relocations in the Life Course. In L. G. van Wissen, \& P. Dykstra (Eds.), Population Issues (pp. 159-186, The Plenum Series on Demographic Methods and Population Analysis): Springer Netherlands.

Musterd, S., Galster, G., \& Andersson, R. (2012). Temporal dimensions and measurement of neighbourhood effects. Environment and Planning-Part A, 44(3), 605.

Sharkey, P., \& Elwert, F. (2011). The legacy of disadvantage: Multigenerational neighborhood effects on cognitive ability. AJS; American journal of sociology, 116(6), 1934.

Sharkey, P., \& Faber, J. W. (2014). Where, when, why, and for whom do residential contexts matter? Moving away from the dichotomous understanding of neighborhood effects. Annual Review of Sociology(0).

Small, M. L., \& Feldman, J. (2012). Ethnographic evidence, heterogeneity, and neighbourhood effects after moving to opportunity. In Neighbourhood effects research: New perspectives (pp. 57-77): Springer.

van Ham, M., Hedman, L., Manley, D., Coulter, R., \& Östh, J. (2014). Intergenerational transmission of neighbourhood poverty: an analysis of neighbourhood histories of individuals. Transactions of the Institute of British Geographers, 39(3), 402-417, doi:10.1111/tran.12040.

van Ham, M., \& Manley, D. (2012). Neighbourhood effects research at a crossroads. Ten challenges for future research. Environment and Planning A, 44(12), 2787-2793.

Van Ham, M., \& Tammaru, T. (2016). New Perspectives on Ethnic Segregation over Time and Space: A Domains Approach. Urban Geography 1-10

Wheaton, B., \& Clarke, P. (2003). Space Meets Time: Integrating Temporal and Contextual Influences on Mental Health in Early Adulthood. American Sociological Review, 68(5), 680-706, doi:10.2307/1519758.

Willekens, F. J. (1999). The life course: models and analysis. In Population Issues (pp. 2351): Springer. 